\title{
ТЕХНОЛОГИЯ МАШИНОСТРОЕНИЯ
}

DOI: 10.26730/1999-4125-2019-6-5-13

УДК 621.9.048.6:621.794

\section{ВЛИЯНИЕ ВИБРАЦИОННЫХ ТВЕРДОСМАЗОЧНЫХ ПОКРЫТИЙ НА КАЧЕСТВО ПОВЕРХНОСТИ И ЭКСПЛУАТАЦИОННЫЕ СВОЙСТВА ДЕТАЛЕЙ ТРАНСПОРТНЫХ МАШИН}

\section{INFLUENCE OF VIBRATION SOLID LUBRICANTS COATINGS ON SURFACE QUALITY AND OPERATIONAL PROPERTIES OF TRANSPORT MACHINE PARTS}

\author{
Иванов Владимир Витальевич, \\ доктор техн. наук, доцент, e-mail: vivanov_dstu@mail.ru \\ Vladimir V. Ivanov, Dr. Sc. in Engineering, Associate Professor \\ Попов Сергей Иванович, \\ канд. техн. наук, доцент \\ Sergey I. Popov, C. Sc. in Engineering, Associate Professor \\ Донцов Николай Сергеевич, \\ канд. техн. наук, доцент, \\ Nikolay S. Dontsov, C. Sc. in Engineering, Associate Professor, \\ Курская Инна Александровна, \\ аспирант \\ Kurskaya Inna Alexandrovna, Postgraduate
}

Донской государственный технический университет, 344000, Россия, г. Ростов-на-Дону, пл. Гагарина, 1

Don State Technical University, pl. Gagarina, Rostov-na-Donu, 1344000, Russian Federation

\section{Аннотация:}

В статье рассмотрены технологические возможности применения вибрационных механохимических твердосмазочных покрытий на основе $M_{0} S_{2}$ для повышения качества поверхности и эксплуатационных свойств деталей. Установлено, что вибрачиионые твердосмазочные механохимические покрытия на основе дисульфида молибдена работают не только в воздушной среде, но и в среде масла. Применение покрытия в парах трения увеличивает срок службы изделия, а с внедрением наноразмерных структур открывает уникальные возможности для получения нового уровня свойств: высокой прочности, долговечности, износостойкости достаточно высокой пластичности, сохраняя при этом высокие эксплуатационные свойства изделий.

Ключевые слова: вибраџионная обработка, вибрациионые механохимические покрытия, твердые смазки, качество поверхности.

Abstract:

The article discusses the technological possibilities of using vibration mechanochemical solid lubricant coatings based on mos2 to improve the surface quality and operational properties of parts. It has been established that vibrating solid lubricant mechanochemical coatings based on molybdenum disulfide work not only in air but also in oil. The use of coatings in friction pairs increases the service life of the product, and with the introduction of nanoscale structures it opens up unique opportunities for obtaining a new level of properties: high strength, durability, wear resistance of sufficiently high ductility, while maintaining high operational properties of the products

Key words: vibration treatment, the vibration mechano-chemical coating of solid lubricant, surface quality. 


\section{Введение}

В современной специальной литературе повышению конкурентоспособности машин и агрегатов уделяют должное внимание. Разработка и внедрение в производство практичных, высокоэффективных технологических процессов, обеспечивающих высокое качество, эксплуатационные свойства и товарный вид выпускаемой продукции, является одним из приоритетных направлений прикладной науки.

Важным условием решения этих задач является совершенствование и развитие финишных методов обработки и нанесения покрытий.

Одним из эффективных способов обработки, позволяющих комбинировать процессы виброотделки деталей с одновременным нанесением на них покрытий, является вибрационная обработка.

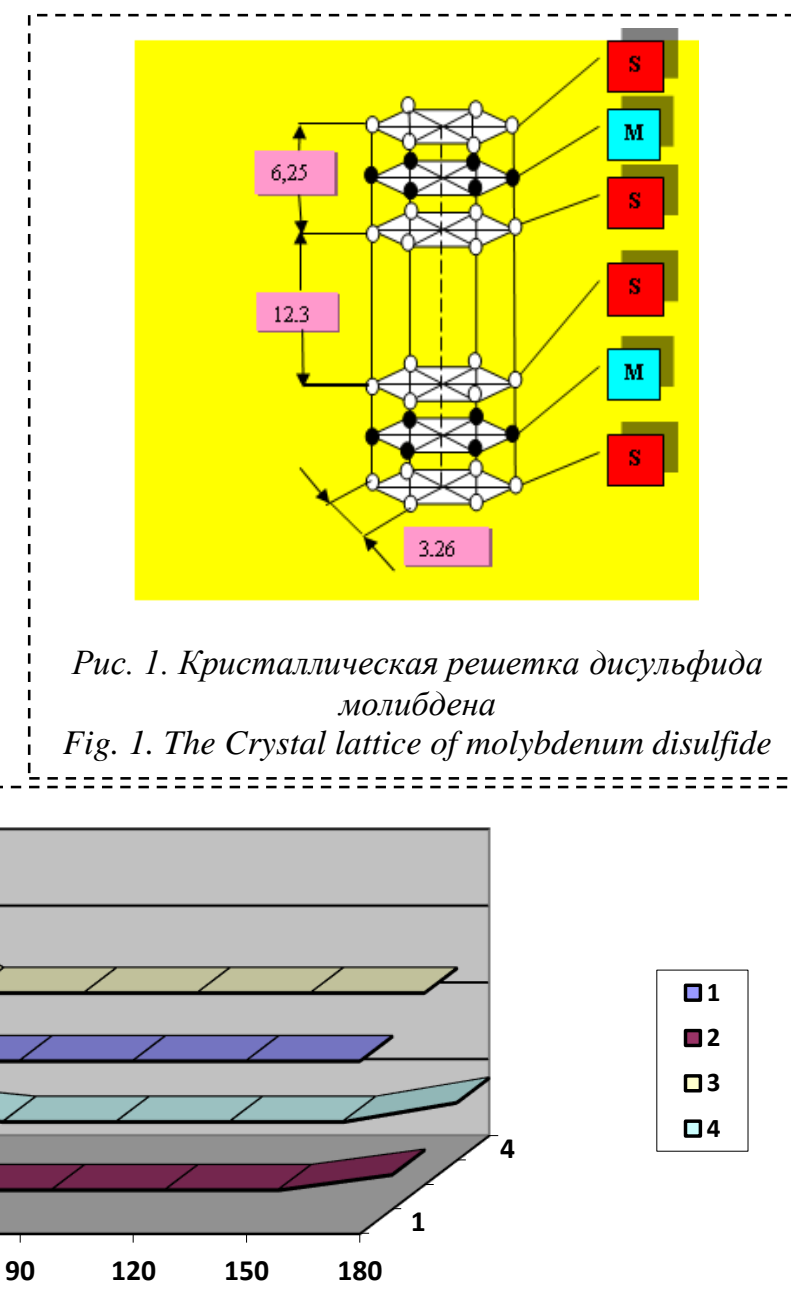

Рис. 2. Исследование коэффициента трения пар:

1 - ШХ15-40X-исходные; 2 - ШХ15 - покрытие $\mathrm{MoS}_{2}-40 X$-исходные; 3-40Х-чугун СЧ21-40-исходные;

4-40X-nокрытие $\mathrm{MoS}_{2}$ - чугун С421-40-исходные.

Fig. 2. Study of the coefficient of friction of pairs:

1-WX15-40X-initial; 2 - WX15 - coating MoS2-40X-initial;

3-40X-cast iron SCH21-40-original;

4-40X-coating MoS2-cast iron SCH21-40-original.

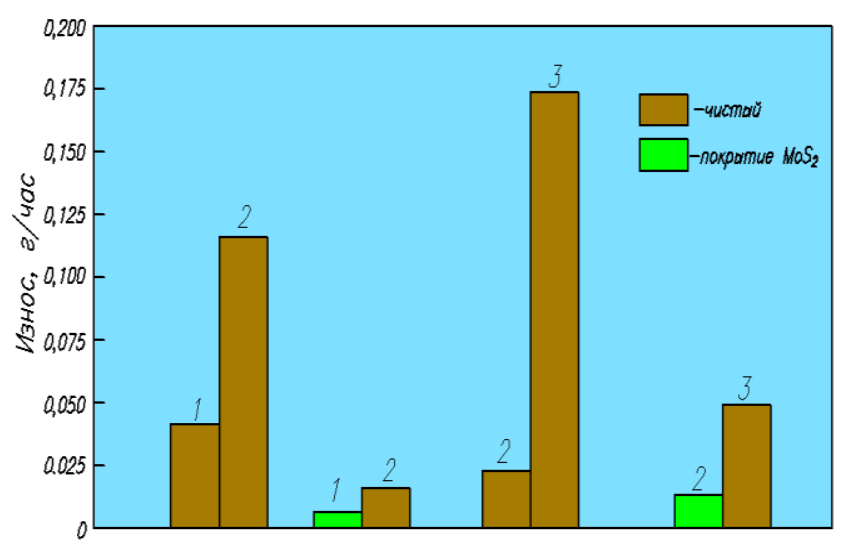

Рис. 3. Исследование износостойкости пар трения образцов:

1 - сталь ШХ15; 2 - сталь 40X;3 - чугун СЧ21-40.

Fig. 3. Research of wear resistance of pairs of friction of samples: 1 - steel SHX15; 2 - steel 40X; 3 - cast iron SCH21-40. 
Вестник Кузбасского государственного технического университета. 2019. № 6, с.5-13

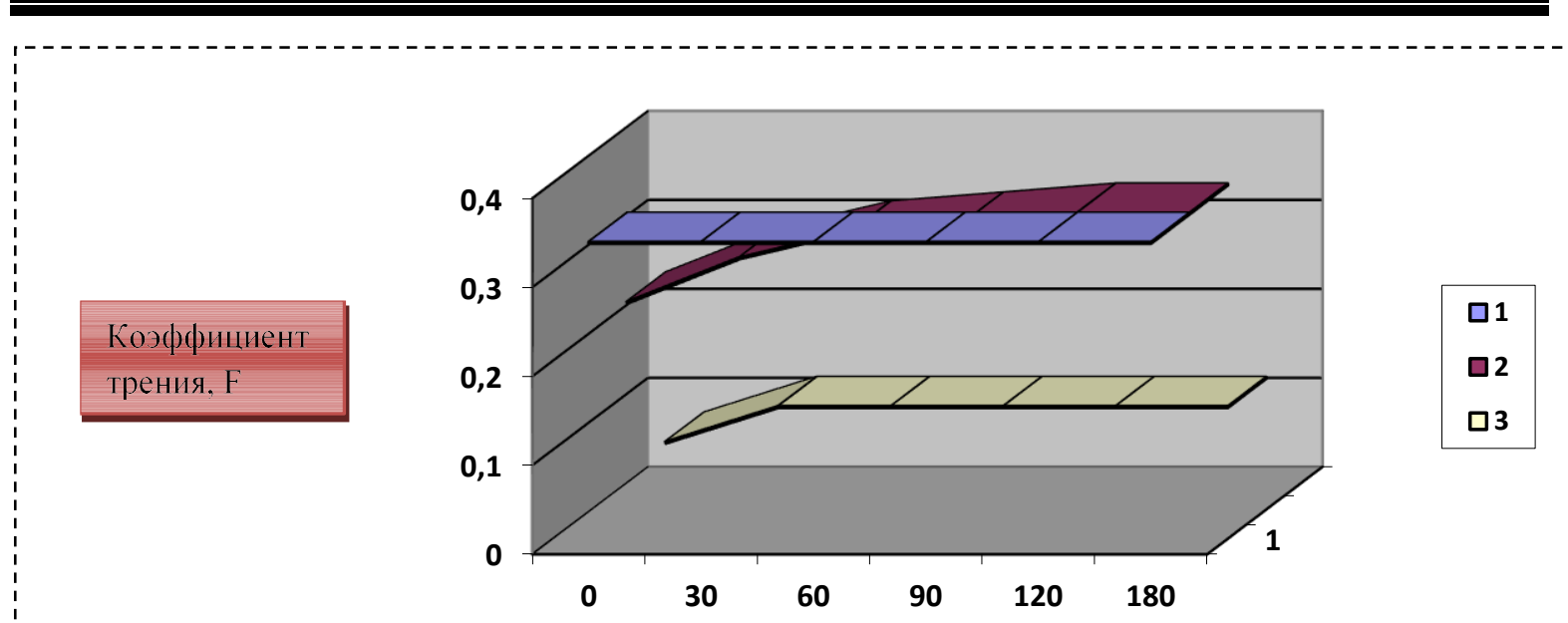

Рис. 4. Результаты испытаний образияов из титановых сплавов ВТ-20 при трении качения с 20\%-ылм проскальзыванием,

нагрузке 40кГ(q=900кГc/см) - при комнатной температуре без смазки;

1 -исходные; 2 - виброупрочненные; 3 - покрытые $\mathrm{MoS}_{2}$.

Fig. 4. Test results of samples from titanium alloys VT-20 at rolling friction with $20 \%$ slippage, load $40 \mathrm{~kg}$ $(q=900 \mathrm{kgs} / \mathrm{cm})$ - at room temperature, without lubrication;

1-initial; 2 -vibration hardened; 3 -covered $\mathrm{MoS}_{2}$.
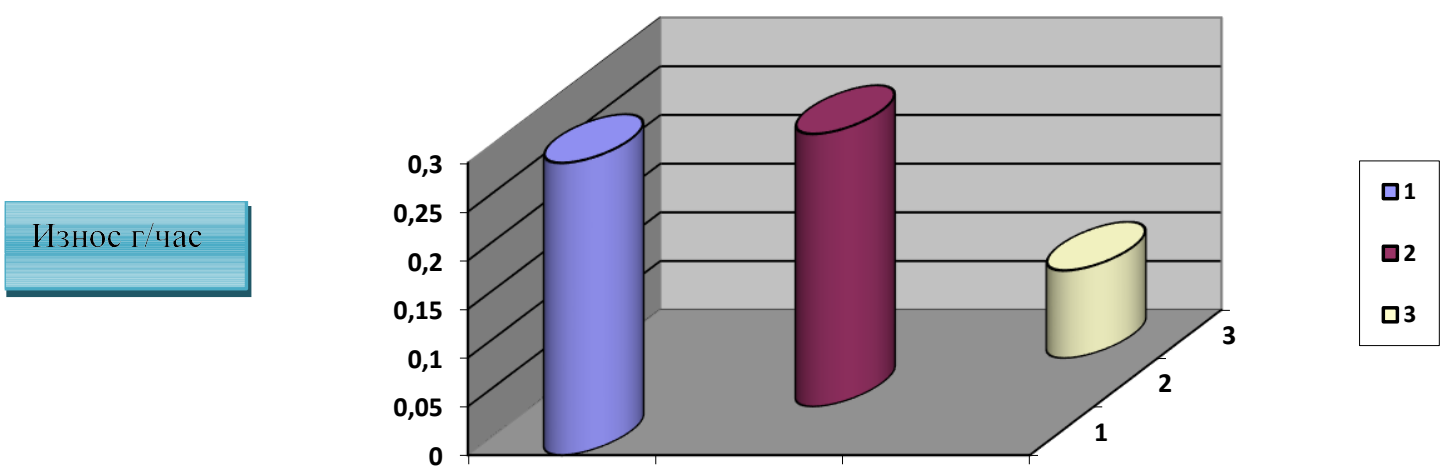

Рис. 5. Износостойкость пар трения образиов из сплава ВТ-20 и сталь 1 Х12Н2ВМФ;

1 -исходные; 2 - виброупрочненные; 3 - покрытые $\mathrm{MoS}_{2}$.

Fig. 5. Wear resistance of friction pairs of samples from alloy VT-20 and steel 1H12N2VMF; 1 - initial; 2 vibration hardened; $3-\mathrm{MoS}_{2}$ coated.

Предметом наших исследований является твердосмазочное покрытие на основе $\mathrm{Mos}_{2}$, формируемое на поверхности детали в условиях виброобработки свободнодвижущимися инденторами. Интерес многих исследователей к твердосмазочным покрытиям на основе дисульфида молибдена обусловлен его уникальными свойствами, которые способствуют повышению износостойкости ответственных деталей, входящих в пары трения различных изделий. Дисульфид молибдена имеет гексагональную слоистую решетку в форме призматического шестигранника (рис.1) [1-10]. Такое строение кристаллической решетки $\mathrm{MoS}_{2}$ обеспечивает наличие важных для смазочных материалов высоких адгезионных свойств.
Дисульфид молибдена обладает слоистой структурой, в которой есть «прочные» и «плотные» слои, в достаточно большой степени удаленные друг от друга.

При этом в слое, покрывающем поверхность трения, имеются сильные связи, тогда как связи между слоями слабые. Такие свойства твердосмазочного покрытия обеспечивают «легкое» скольжение трущихся поверхностей друг относительно друга, существенно снижая коэффициент трения и изнашивание пары трения. Высокая адгезия дисульфида молибдена к металлам обусловлена прочными молекулярными связями, образуемыми атомами серы с металлом [2]. 
Вестник Кузбасского государственного технического университета. 2019. № 6, с.5-13

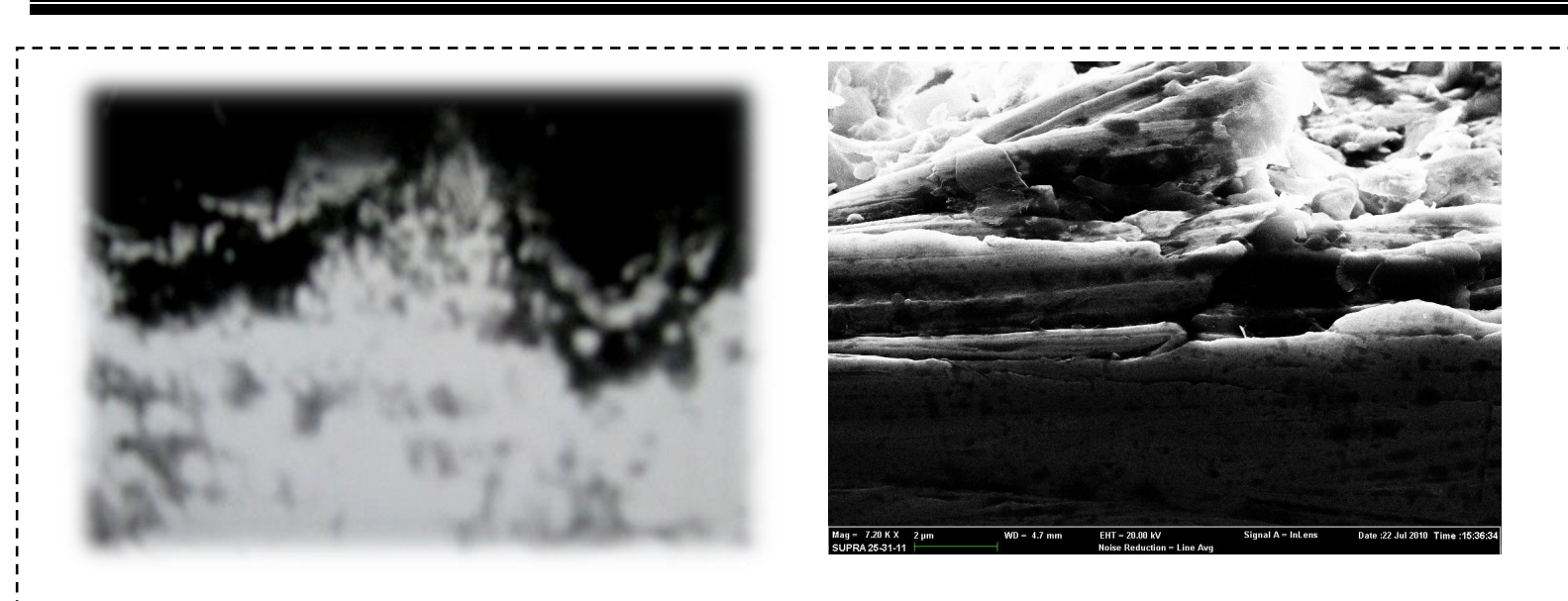

Рис. 6. Поверхность микрошлифа стали 45 (HRC 28) с внедренными частицами порошка MoS2, × 500 a), б) получены на аналитическом автоэмиссионном электронном микроскопе Zeiss SUPRA25

Fig. 6. The surface of the 45 (HRC 28) steel microscape with embedded MoS2 powder particles, $\times 500$ a), b) were obtained on the Zeiss SUPRA25 analytical autoemission electron microscope
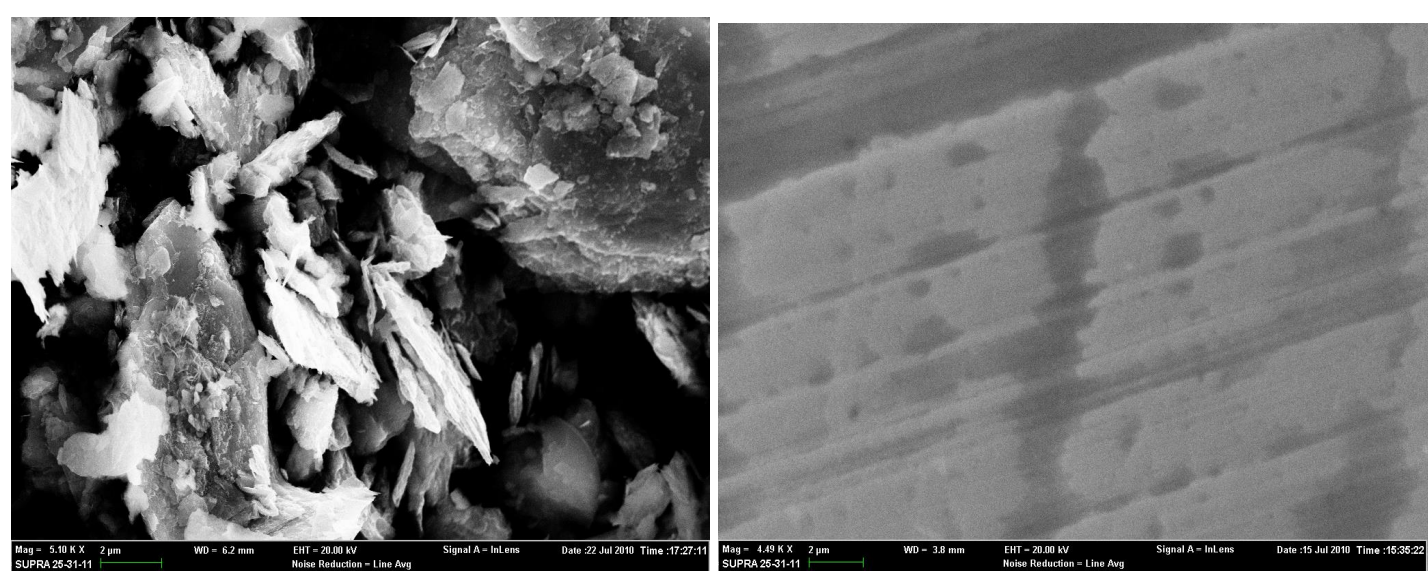

Рис. 7(б) - Порошок $\mathrm{MoS}_{2}$ Рис. 7 (а) - Исходный образеи Сталь3
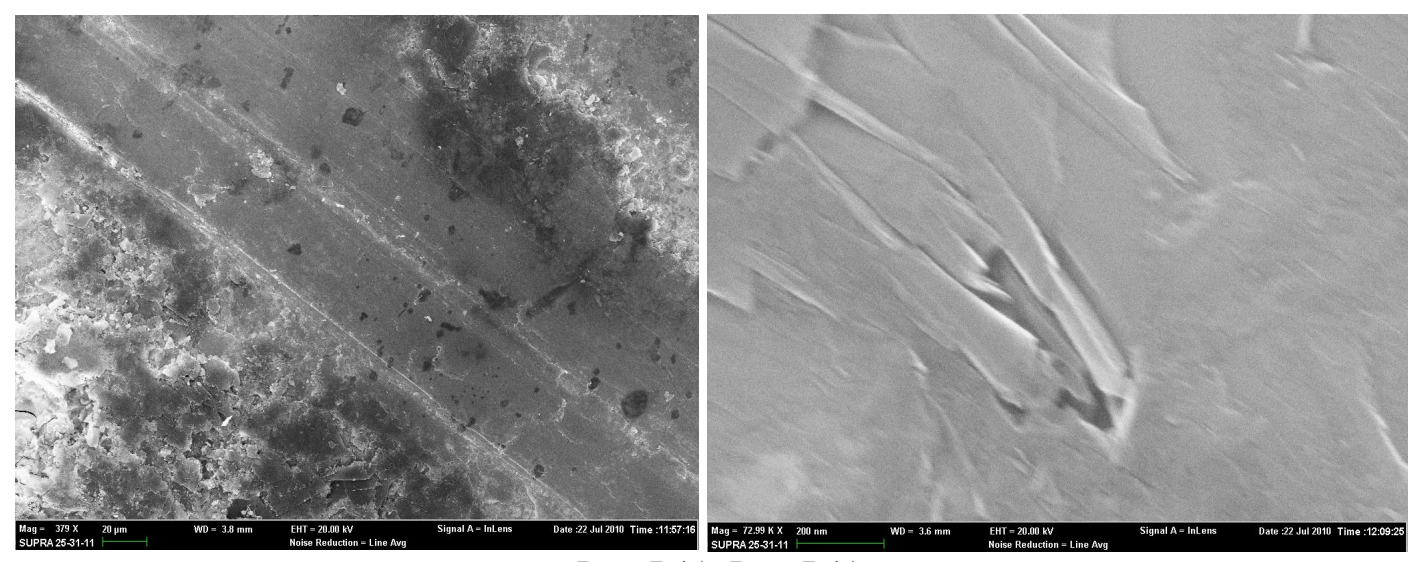

Puc. 7 (в) Puc. 7 (2)

Исследование эксплуатационных

качества свойст

вибрационных

Экспериментальные

исследования эксплуатационных характеристик проводились на машине трения СМЦ-2 по стандартной методике. Результаты исследований представлены на рис. 2, $3,4,5$.

Результаты

проводимых

исследований показали, что полученное в процессе вибрационной обработки твердосмазочное покрытие $\mathrm{MoS}_{2}$ приводит к снижению коэффициента трения и повышению износостойкости пар трения при работе не только в воздушной среде, но и в среде масла. Износ при работе в течение трех часов практически не отмечен. Экспериментально подтверждено, что наличие слоев различных атомов в структуре 
Вестник Кузбасского государственного технического университета. 2019. № 6, с.5-13

Иванов В.В., Попов С.И., Донцов Н.С., Курская И.А. Влияние вибрационных твердосмазочных ...

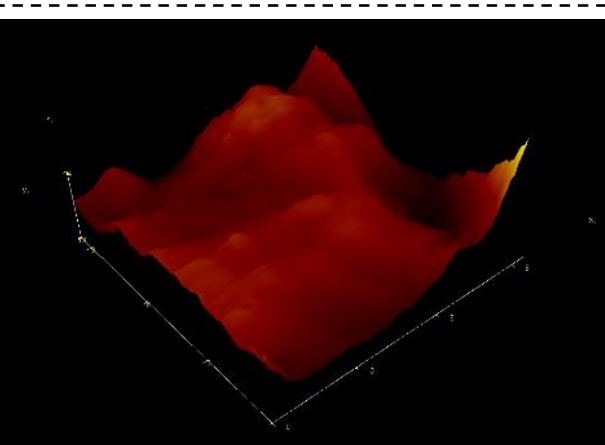

(a)

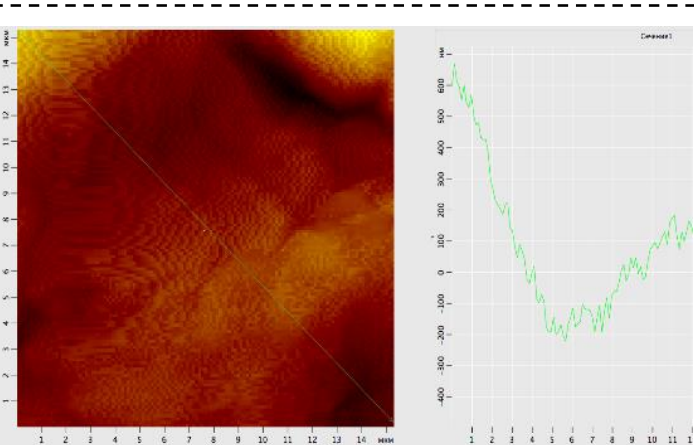

(б)

Рис. 8. 3D-модель исходной поверхности(а); Микрорельеф исходной поверхности(б). Fig. 8. 3D model of the initial surface(a); Microrelief of the initial surface(b).
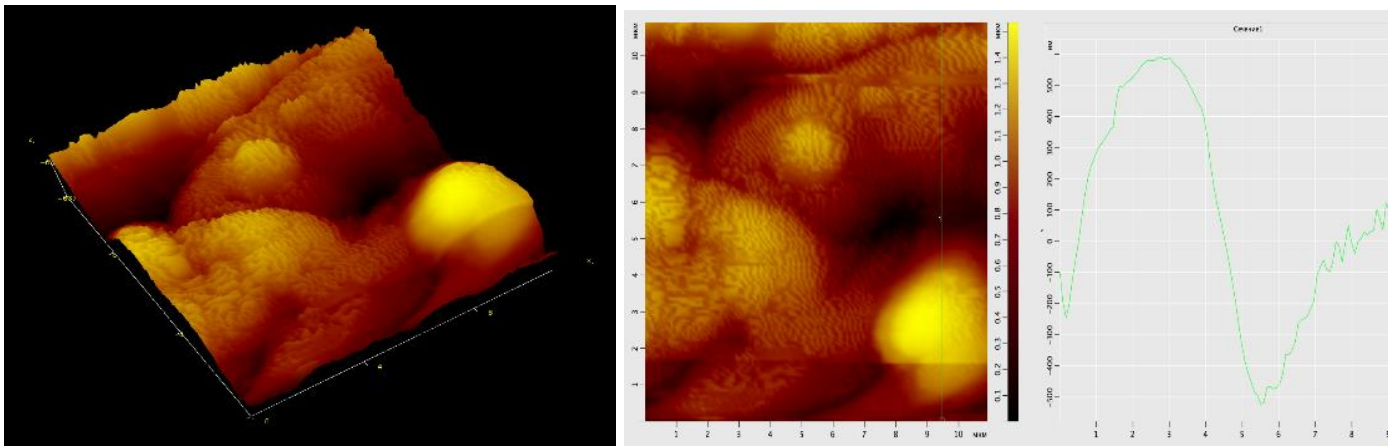

(a) (б)

Pис. 9. 3D-модель поверхности с нанесенным $\mathrm{MoS}_{2}($ a); (б) - Микрорельеф поверхности с нанесенным $\mathrm{MoS}_{2}$.

Fig 9. 3D model of the surface with applied $\mathrm{MoS}_{2}(a) ;(b)$ - Microrelief of the surface with applied $\mathrm{MoS}_{2}$.
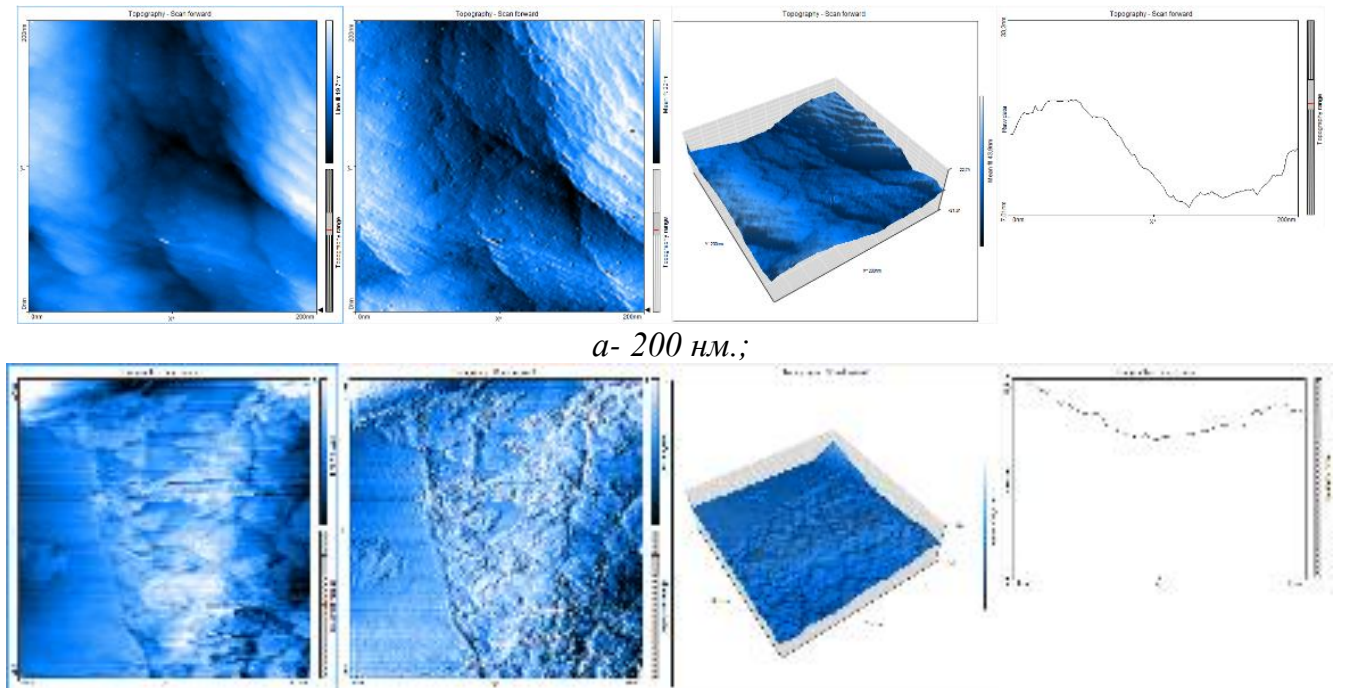

$$
\sigma-200 \text { нм.; }
$$

Рис. 10. а) Нанорельеф исходной поверхности стали 45; б) Нанорельеф поверхности с нанесенным

\begin{abstract}
дисульфида молибдена создает условия легкого
\end{abstract} скольжения.

Большое влияние на антифрикционные свойства покрытия оказывает наноразмерность и ориентация его частиц, а также нанорельеф поверхности основы. В процессе формирования покрытия дисульфида молибдена вибрационным способом обеспечивается ориентация частиц базовыми плоскостями параллельно плоскости скольжения, процесс приработки покрытия в этом случае практически отсутствует [16-21].

В зависимости от условий эксплуатации и материала пар трения коэффициент трения снижается в 3-9 раз, а увеличение их 
износостойкости - в 4-20 раз.

С целью более глубокого исследования поверхности использовался электронный микроскоп SUPRA25, позволяющий изучать поверхность металла, материал покрытия, вести непрерывный контроль процесса, электроннолучевую литографию и наблюдение материалов с ультрамалыми размерами (нм). Исследования поверхностного слоя проводили сканирующим зондовым микроскопом Nanoeducator (NT-MDT), нанопрофиль поверхности - на туннельном микроскопе PHYWE.

На рис. 6 и 7 представлена серия фотографий, иллюстрируемых состояние поверхности образца из стали 45 и порошка $\mathrm{MoS}_{2}$ в исходном состоянии и после нанесения покрытия $\mathrm{MoS}_{2}$. Снимки произведены с различным увеличением и с различных позиций (изменением наклона предметного стола). Адсорбированные частицы твердой смазки не имеют определенной ориентации (рис. 6а), но в зоне контакта благодаря сближению и скользящим ударам индентора частицы ориентируются базовыми плоскостями параллельно обрабатываемой поверхности, о чем говорят блестящие участки на поверхности покрытия, хорошо видимые на микрофотографии (рис. 6, б).

Полученные фотографии дают наглядное представление о характере рельефа покрываемой поверхности и твердосмазочного покрытия, раскрывают механизм образования при механическом (виброударном) воздействии в среде стальных инденторов диаметром $3 \ldots .5$ мм и ее влияние на бинарную смесь и порошок дисульфида молибдена. [11-16]. На (рис. 7а) четко видны параллельные линии на металле, оставленные после механической обработки [3]. На (рис. 7б) видны размеры и расположение порошка (хаотичное). После нанесения покрытия (рис. 7в) механически была удалена часть порошка, таким образом образовалась четкая граница «металл покрытие», отчетливо видная на фотографии, что дало возможность увидеть боковой шлиф, который подтвердил ориентацию частиц $\mathrm{MoS}_{2}$ относительно вращения детали. Кроме того, в результате проведенных исследований установлено, что образуемый в процессе вибрационной обработки слой твердой смазки дисульфида молибдена покрывается тонкой пленкой, имеющей ориентацию частиц базовыми плоскостями параллельно поверхности трения (рис. 7г).

Исследования микрорельефа поверхности проводились на базе (МРЦКП ДГТУ) с использованием сканирующего зондового микроскопа Nanoeducator (NT-MDT), результаты представлены на рис. 9, 10. В качестве исходной поверхности, удовлетворяющей требованиям оборудования, использовались шлифованные образцы 10/10 мм из стали 45.

Как видно из представленных рисунков, поверхность с покрытием дисульфида молибдена $\left(\mathrm{MoS}_{2}\right)$ по сравнению с необработанной становиться более пологой, микровыступы скруглены. Такое строение пленки, как показал анализ, обусловлено включением в нее наноразмерных структур. Внедрение наноразмерных структур в вибрационное механохимическое покрытие повышает эффективность твердых смазок; установлено, что с уменьшением размера зерна от 1 мкм до $2 \mathrm{Hм}$ объемная доля межзеренного вещества увеличится до $88 \%$, это позволяет получать покрытия с уникально высокими свойствами. Например, их долговечность в 2-7 раз выше, чем твердость крупнозернистых покрытий, прочность в 1.5-2 раза выше, а при уменьшении размера зерна от 10 мкм до 10 нм скорость износа покрытия уменьшается в 10 paz.

\section{Выводы}

Установлено, что вибрационные твердосмазочные механохимические покрытия на основе дисульфида молибдена работают не только в воздушной среде, но и в среде масла. Нанесение покрытия не требует сложного оборудования и высокой квалификации рабочих. Применение покрытия в парах трения увеличивает срок службы изделия в 10-20 раз, а с внедрением наноразмерных структур открывает уникальные возможности для получения нового уровня свойств: высокой прочности, долговечности, износостойкости достаточно высокой пластичности, сохраняя при этом высокие эксплуатационные свойства изделий.

\section{СПИСОК ЛИТЕРАТУРЫ}

1. Бабичев А.П., Бабичев И.А. Основы вибрационной технологии. Издание второе, переработанное и дополненное - Ростов н/Д: Издательский центр ДГТУ, 2008. - 694 с.

2. Иванов В.В., Селеменев М.Ф., Марченко Ю.В. Формирование вибрационных механохимических твердосмазочных покрытий на основе дисульфида молибдена // Фундаментальные и прикладные проблемы техники и технологии.- 2011.- № 2 (286).- С. 73-78.

3.Бабичев А.П., Иванов В.В. Булгаков Я.С. Исследование коэффициента трения, износостойкости и микро/нанопрофиля поверхности вибрационного механохимического покрытия дисульфида молибдена 
MoS2(статья). Журнал «Известия Орел ГТУ» № 1 (285) Орел, 2011. Фундаментальные и прикладные проблемы техники и технологии.

4.Ivanov V.V., Popov S.I., Dontsov N.S., Essola D. Zinc Coating Obtained in the Result of the Mechanochemical Effects in Vibrodynamic the Setups of Various Types // X International Scientific and Practical Conference «Innovations in Mechanical Engineering» (ISPCIME-2019): MATEC Web of Conferences, Vol. 297, 2019. doi:org/10.1051/matecconf/201929701003

5.Ivanov V.V., Popov S.I., Kirichek A.V. Investigation of optimal chemical composition of cast aluminum alloys for vibrational mechanical-chemical polishing and deposition of protective and decorative coatings // XI International Conference on Mechanical Engineering, Automation and Control Systems (MEACS 2017): IOP Conference Series: Materials Science and Engineering, Vol. 327, 2018. doi:10.1088/1757-899X/327/3/032026

6.Ivanov V.V., Dontsov N.S., Kirichek A.V. Technological features of metallic zinc coatings obtained during mechanochemical synthesis, implemented in conditions of vibro-wave technological systems // XI International Conference on Mechanical Engineering, Automation and Control Systems (MEACS 2017): IOP Conference Series: Materials Science and Engineering, Vol. 327, 2018. doi:10.1088/1757-899X/327/3/032025

7.Ivanov V.V., Popov S.I., Kirichek A.V. Qualitative Characteristics of $\mathrm{MoS}_{2}$ Solid-Lubricant Coating Formed by Vibro-Wave Impact of Free-Moving Indenters // Key Engineering Materials, Vol. 736, pp. 18-22, 2017. DOI:10.4028/ www.scientific.net/ KEM.736.18

8.Ivanov V.V., Dontsov N.S., Kirichek A.V. Mechanical Zinc Coating Procedure under Conditions of Vibration Mechanical-Chemical Impact // Key Engineering Materials, Vol. 736, pp. 105-109, 2017. DOI: 10.4028/ www.scientific.net/ KEM.736.105

9.Иванов В.В., Лебедев В.А., Попов С.И., Донцов Н.С., Останин О.А. Анализ применения химикомеханических вибрационных покрытий в машиностроении // Горное оборудование и электромеханика. 2019. - №1. - C. 3-12.

10.Иванов В.В., Загутин Д.С., Попов С.И., Скудина А.А. Повышение эксплуатационных характеристик и эксплуатационных свойств покрытий, сформированных в условиях вибрационного механохимического воздействия // Инженерный вестник Дона.- 2019.- № 1.

11.Иванов В.В., Загутин Д.С., Попов С.И., Останин О.А. Анализ методов по формированию вибрационных механохимических покрытий // Вестник Кузбасского государственного технического университета.- 2018.- № 5.- С. 106-113.

12.Иванов В.В., Попов С.И., Марченко Ю.В. Использование полимерных рабочих сред для формирования оксидной пленки в условиях виброобработки // Вестник Рыбинской государственной авиационной технологической академии им. П. А. Соловьева.- 2018.- № 1(44).- С. 108-113.

13.Бабичев А.П., Иванов В.В., Попов С.И., Донцов Н.С. Особенности механизма формирования вибрационного химико-механического цинкового покрытия // Упрочняющие технологии и покрытия.2018.- Том 14, № 2(158).- С. 51-54.

14.Марченко Э.В., Попов С.И., Марченко Ю.В., Донцов Н.С., Иванов В.В., Скудина А.А. Технические измерения на транспорте: учеб. пособие.- Ростов н/Д: Издательский центр ДГТУ, 2017.- 81 с.

15.Попов С.И., Рункевич Ю.П., Марченко Ю.В., Валявин В.Ю., Донцов Н.С., Иванов В.В. Технические средства диагностирования транспортных машин: учеб. пособие.- Ростов н/Д: Издательский центр ДГТУ, 2016.- 199 c.

16.Попов С.И., Марченко Ю.В., Донцов Н.С., Иванов В.В., Марченко Э.В. Исследование возможности восстановления стенок цилиндра двигателей внутреннего сгорания (ДВС) за счет применения твердосмазочных материалов на основе дисульфида молибдена // Наукоемкие технологии на современном этапе развития машиностроения: Материалы VIII международной научно-технической конференции, 1921 мая.- М., 2016.- С. 179-181.

17.Иванов В.В., Попов С.И., Валявин В.Ю., Марченко Ю.В., Марченко Э.В. Особенности инструментального обеспечения для формирования вибрационных механохимических покрытий // Мир гальваники.- 2015.- № 1(29).- С.34-38.

18.Иванов В.В. Основы вибрационных химико-механических методов нанесения покрытий: монография.- Ростов н/Д: Издательский центр ДГТУ, 2019.- 205 с.

19.Иванов В.В. Вибрационные методы нанесения покрытий. Цинкование: монография.- Ростов н/Д: Издательский центр ДГТУ, 2010.- 142 с.

20.Иванов В.В., Марченко Э.В., Панфилов А.В. Повышение стойкости стального каната путем нанесения и формирования антифрикционного порошкового покрытия в узлах счалки //Научнотехнический вестник Брянского государственного университета. - 2019. - №2.

21.Короткий А.А., Марченко Э.В., Панфилов А.В. Математическая модель счаливания (сращивания) стального каната //Научно-технический вестник Брянского государственного университета. - 2019. - №3. 


\section{REFERENCES}

1. Babichev A.P., Babichev I.A. Osnovy vibracionnoj tekhnologii. Izdanie vtoroe, pererabotannoe i dopolnennoe - Rostov n/D: Izdatel'skij centr DGTU, 2008. - 694 s.

2. Ivanov V.V., Selemenev M.F., Marchenko YU.V. Formirovanie vibracionnyh mekhanohimicheskih tverdosmazochnyh pokrytij na osnove disul'fida molibdena // Fundamental'nye i prikladnye problemy tekhniki i tekhnologii.- 2011.- № 2 (286).- S. 73-78.

3.Babichev A.P., Ivanov V.V. Bulgakov YA.S. Issledovanie koefficienta treniya, iznosostojkosti i mikro/nanoprofilya poverhnosti vibracionnogo mekhanohimicheskogo pokrytiya disul'fida molibdena MoS2(stat'ya). ZHurnal «Izvestiya Orel GTU» № 1 (285) Orel, 2011. Fundamental'nye i prikladnye problemy tekhniki i tekhnologii.

4.Ivanov V.V., Popov S.I., Dontsov N.S., Essola D. Zinc Coating Obtained in the Result of the Mechanochemical Effects in Vibrodynamic the Setups of Various Types // X International Scientific and Practical Conference «Innovations in Mechanical Engineering» (ISPCIME-2019): MATEC Web of Conferences, Vol. 297, 2019. doi:org/10.1051/matecconf/201929701003

5.Ivanov V.V., Popov S.I., Kirichek A.V. Investigation of optimal chemical composition of cast aluminum alloys for vibrational mechanical-chemical polishing and deposition of protective and decorative coatings // XI International Conference on Mechanical Engineering, Automation and Control Systems (MEACS 2017): IOP Conference Series: Materials Science and Engineering, Vol. 327, 2018. doi:10.1088/1757-899X/327/3/032026

6.Ivanov V.V., Dontsov N.S., Kirichek A.V. Technological features of metallic zinc coatings obtained during mechanochemical synthesis, implemented in conditions of vibro-wave technological systems // XI International Conference on Mechanical Engineering, Automation and Control Systems (MEACS 2017): IOP Conference Series: Materials Science and Engineering, Vol. 327, 2018. doi:10.1088/1757-899X/327/3/032025

7.Ivanov V.V., Popov S.I., Kirichek A.V. Qualitative Characteristics of MoS2 Solid-Lubricant Coating Formed by Vibro-Wave Impact of Free-Moving Indenters // Key Engineering Materials, Vol. 736, pp. 18-22, 2017. DOI:10.4028/ www.scientific.net/ KEM.736.18

8.Ivanov V.V., Dontsov N.S., Kirichek A.V. Mechanical Zinc Coating Procedure under Conditions of Vibration Mechanical-Chemical Impact // Key Engineering Materials, Vol. 736, pp. 105-109, 2017. DOI: 10.4028/ www.scientific.net/ KEM.736.105

9.Ivanov V.V., Lebedev V.A., Popov S.I., Doncov N.S., Ostanin O.A. Analiz primeneniya himikomekhanicheskih vibracionnyh pokrytij v mashinostroenii // Gornoe oborudovanie i elektromekhanika. - 2019. №1. - C. 3-12.

10.Ivanov V.V., Zagutin D.S., Popov S.I., Skudina A.A. Povyshenie ekspluatacionnyh harakteristik i ekspluatacionnyh svojstv pokrytij, sformirovannyh $\mathrm{v}$ usloviyah vibracionnogo mekhanohimicheskogo vozdejstviya // Inzhenernyj vestnik Dona.- 2019.- № 1.

11.Ivanov V.V., Zagutin D.S., Popov S.I., Ostanin O.A. Analiz metodov po formirovaniyu vibracionnyh mekhanohimicheskih pokrytij // Vestnik Kuzbasskogo gosudarstvennogo tekhnicheskogo universiteta.- 2018.- № 5.- S. 106-113.

12.Ivanov V.V., Popov S.I., Marchenko YU.V. Ispol'zovanie polimernyh rabochih sred dlya formirovaniya oksidnoj plenki v usloviyah vibroobrabotki // Vestnik Rybinskoj gosudarstvennoj aviacionnoj tekhnologicheskoj akademii im. P. A. Solov'eva.- 2018.- № 1(44).- S. 108-113.

13.Babichev A.P., Ivanov V.V., Popov S.I., Doncov N.S. Osobennosti mekhanizma formirovaniya vibracionnogo himiko-mekhanicheskogo cinkovogo pokrytiya // Uprochnyayushchie tekhnologii i pokrytiya.2018.- Tom 14, № 2(158).- S. 51-54.

14.Marchenko E.V., Popov S.I., Marchenko YU.V., Doncov N.S., Ivanov V.V., Skudina A.A. Tekhnicheskie izmereniya na transporte: ucheb. posobie.- Rostov n/D: Izdatel'skij centr DGTU, 2017.- $81 \mathrm{~s}$.

15.Popov S.I., Runkevich YU.P., Marchenko YU.V., Valyavin V.YU., Doncov N.S., Ivanov V.V. Tekhnicheskie sredstva diagnostirovaniya transportnyh mashin: ucheb. posobie.- Rostov n/D: Izdatel'skij centr DGTU, 2016.- 199 s.

16.Popov S.I., Marchenko YU.V., Doncov N.S., Ivanov V.V., Marchenko E.V. Issledovanie vozmozhnosti vosstanovleniya stenok cilindra dvigatelej vnutrennego sgoraniya (DVS) za schet primeneniya tverdosmazochnyh materialov na osnove disul'fida molibdena // Naukoemkie tekhnologii na sovremennom etape razvitiya mashinostroeniya: Materialy VIII mezhdunarodnoj nauchno-tekhnicheskoj konferencii, 19-21 maya.- M., 2016.S. 179-181.

17.Ivanov V.V., Popov S.I., Valyavin V.YU., Marchenko YU.V., Marchenko E.V. Osobennosti instrumental'nogo obespecheniya dlya formirovaniya vibracionnyh mekhanohimicheskih pokrytij // Mir gal'vaniki.- 2015.- № 1(29).- S.34-38.

18.Ivanov V.V. Osnovy vibracionnyh himiko-mekhanicheskih metodov naneseniya pokrytij: monografiya.Rostov n/D: Izdatel'skij centr DGTU, 2019.- 205 s. 
19.Ivanov V.V. Vibracionnye metody naneseniya pokrytij. Cinkovanie: monografiya.- Rostov n/D: Izdatel'skij centr DGTU, 2010.- $142 \mathrm{~s}$.

20.Ivanov V.V., Marchenko E.V., Panfilov A.V. Povyshenie stojkosti stal'nogo kanata putem naneseniya i formirovaniya antifrikcionnogo poroshkovogo pokrytiya $\mathrm{v}$ uzlah schalki //Nauchno-tekhnicheskij vestnik Bryanskogo gosudarstvennogo universiteta. - 2019. - №2.

21.Korotkij A.A., Marchenko E.V., Panfilov A.V. Matematicheskaya model' schalivaniya (srashchivaniya) stal'nogo kanata //Nauchno-tekhnicheskij vestnik Bryanskogo gosudarstvennogo universiteta. - 2019. - №3.

Поступило в редакцию 18.12.2019 Received 18 December 2019 